\title{
PATIENT RELATED FACTORS FOR DELAY IN TUBERCULOSIS DETECTION AND TREATMENT IN JAMMU \& KASHMIR STATE, INDIA
}

\author{
Rohul Jabeen Shah', Anjum Bashir Fazili², Abid Ali Mir³, Qazi Mohamad Iqbal ${ }^{4}$ \\ ${ }^{1}$ Additional Professor, Department of Community Medicine, SKIMS, Soura, Jammu and Kashmir. \\ ${ }^{2}$ Additional Professor, Department of Community Medicine, SKIMS, Soura, Jammu and Kashmir. \\ ${ }^{3}$ Assistant Surgeon, DHS. \\ ${ }_{4}^{4}$ Senior Resident, Department of Community Medicine, SKIMS, Soura, Jammu and Kashmir.
}

\section{ABSTRACT}

\section{BACKGROUND}

This study was conducted with an aim of understanding the patient related factors that influence timely diagnosis and case detection rate in Jammu and Kashmir.

\section{MATERIALS AND METHODS}

This cross-sectional study was conducted in sixteen designated microscopy centres that is equal to $20 \%$ of all DMC's in Kashmir Valley. A multistage random sampling procedure was used to select the DMC's. The diagnosed TB patients of the selected DMC's formed the unit of the study.

\section{RESULTS}

Out of 231 registered TB patients, $86.9 \%$ were sputum positive. The females outnumbered males. Patient's age ranged from 5 - 80 years with a mean age of 38 years; $63.2 \%$ of patients belonged to the productive age group (15 to 45 years). Despite that $98.3 \%$ of patients were concerned about their health, only $21.6 \%$ of them had sought treatment within 1st week of appearance of symptoms, while $62.8 \%$ had delayed TB treatment seeking. Only $29.4 \%$ were referred by health workers for diagnosis and treatment of TB. Out of those who had a delay in diagnosis, $44.4 \%$ had reported to a private facility without being diagnosed for TB over there, while $35.6 \%$ had neglected their symptoms initially and sought treatment late. In children less than 15 years, urban dwellers and unemployed visiting a private facility for initial care were the main reason of delay; $23.5 \%$ of rural people reported financial reason for delay as also $46.6 \%$ of unemployed had the same reason. A small percentage of people (12.1\%) had health system related delay. Knowledge about various aspects of TB was also poor among these patients.

\section{CONCLUSION}

The study revealed a significant delay in TB detection in studied patients. The main determinants of delay were: socio-demographic, economic, gender (female) seeking initial care from private practitioners and neglecting their TB symptoms due to poor knowledge of the disease. Rural, illiterate and employed people depicted more delay than urban, literate and unemployed. Once diagnosed, TB treatment was initiated within a reasonable period of time.

\section{KEYWORDS}

Tuberculosis, Delayed Treatment, Health Seeking Behaviour.

HOW TO CITE THIS ARTICLE: Shah RJ, Fazili AB, Mir AA, et al. Patient related factors for delay in tuberculosis detection and treatment in Jammu \& Kashmir state, India. J. Evolution Med. Dent. Sci. 2016;5(94):6962-6969, D0I: 10.14260/Jemds/2016/1575

\section{BACKGROUND}

Worldwide, 9.6 million people are estimated to have fallen ill with TB in 2014. India accounts for $23 \%$ of the global burden. India is implementing WHO endorsed DOTS strategy under a National Programme RNTCP, which was initially started as pilot project (1993 - 97), and the coverage of the same was extended to the whole country in the year 2006. As per current WHO estimates, India's TB control programme is on track as far as reduction in disease burden is concerned. There is 58\% reduction in TB mortality rate by 2014 as compared to 1990

Financial or Other, Competing Interest: None.

Submission 19-10-2016, Peer Review 12-11-2016,

Acceptance 18-11-2016, Published 24-11-2016.

Corresponding Author:

Dr. Rohul Jabeen Shah,

Additional Professor,

Department of Community Medicine,

SKIMS, Soura-190011,

Jammu and Kashmir.

India.

E-mail:rjsskims@gmail.com

DOI: $10.14260 /$ jemds $/ 2016 / 1575$

(c) (i) $\$$ level. Similarly, there is $55 \%$ reduction in TB prevalence rate by 2014 as compared to 1990 level and also the incidence is on declining trend. India is a signatory to World Health Assembly, which has endorsed Sustainable Development Goals and global 'End TB Strategy' that calls for a world free of tuberculosis with measurable aims of $50 \%$ and $75 \%$ reduction in incidence and related deaths respectively by 2025 and corresponding reductions of $90 \%$ and $95 \%$ by 2035 as well as zero catastrophic expenditure due to TB.(1)

Despite there being a decline in prevalence as well as TB related mortality, India still has the highest TB burden in the world and the disease kills two people every three minutes. The national TB control program (RNTCP) uses a passive system for diagnosing TB patients. The design of the system is such that it waits for patients to walk into the centres to get tested. It is well known that patients walk into these centres quite late and in the process they end up infecting many people.(2) Delayed diagnosis of TB can enhance the transmission of infection, worsen the disease, increase the risk of death and may be a reason why TB incidence has not declined substantially despite the global scale-up of DOTS.(3) 
Early case detection and treatment is critical for controlling tuberculosis. Studies suggest that diagnosis of TB is often delayed and one major reason is repeated visits at the same healthcare level and non-specific antibiotic therapies. Overall diagnostic delay has been attributed to both patients and the health system.(4) Other possible reasons for low case detection rate and delayed treatment have been identified. They include poor understanding of TB and its symptoms in the general population, poor knowledge where to seek care, poor health service infrastructure with limited outreach, barriers to access, poor diagnostic quality, limited human resource for health, poor TB knowledge amongst health providers, perverse incentive systems for providers that foster us of inappropriate medical technologies, poor coordination of health services and poor information systems including notification and referral routines. These factors may be different in different settings and they need to be identified by analysing the gaps and barriers for early case detection.(5)

Early diagnosis and prompt pharmacological treatment initiation are essential for effective disease control. Knowledge of the factors associated with delayed diagnosis can be important in order to indicate potential strategies to reduce this delay. (6)

The study was conducted with an aim of understanding the patient factors that influence treatment seeking for tuberculosis and low case detection rate in this part of the country.

\section{MATERIALS AND METHODS}

\section{Setting}

This cross-sectional study was conducted for a period of one year in the year 2012 - 2013 in Kashmir Valley in all the operational districts of RNTCP. Valley has a total of eighty Designated Microscopy Centres (DMC) in 21 Tuberculosis Units (TU's).

\section{Sample Size}

Based on sputum smear positivity, prevalence of $95 / 100,000$ population and Case Detection Rate (CDR) of $42.0 \%(7)$ in the valley and allowing an acceptable error of $5 \%$ with $95 \%$ C. I, sixteen lakh population needed to be surveyed; 16 DMC's that equals $20 \%$ of all DMC's in the valley were to be studied as per study protocol.

\section{Sampling Procedure}

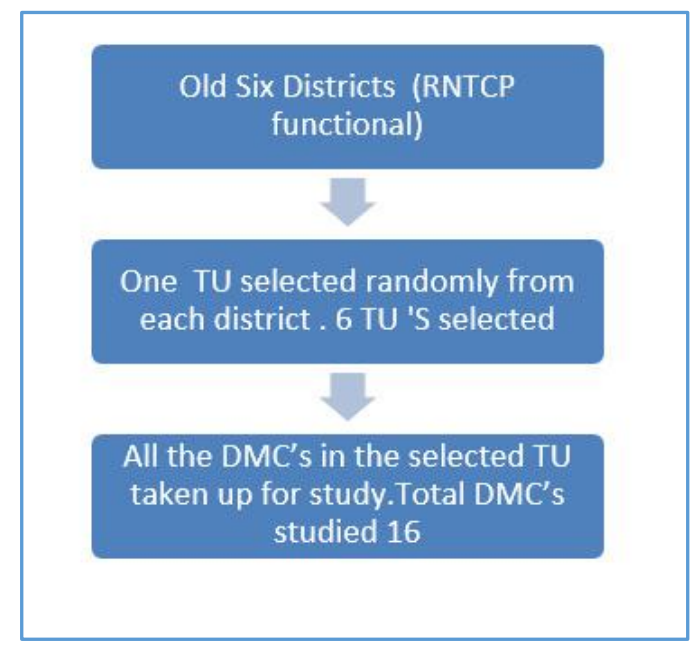

\section{Study Procedure}

Comprehensive study instruments for data collection in accordance with objectives were designed in English. The instruments were tested in actual setting. The desired changes were made till the investigators were satisfied with the quality and details of information required for the purpose of study.

Four numbers of full time field staff were recruited and taught to put the questions in local vernacular language for patients. Confirmed TB patients of the selected DMC's and taking DOTS from DOTS centres attached to these DMC's were enrolled for the study. Patients on DOTS from the previous quarter and the current quarter and who consented to be part of the study formed the study group. A total of $231 \mathrm{~TB}$ patients formed the study group. TB treatment cards and TB registers were also used to identify and locate residences of these patients. Help of DOT providers was taken to interview patients at their respective homes. Informed consent of patients was taken before enrolling them in the study group. The focus was on demographic characteristics, health seeking behaviour, disease history, system attributes, knowledge and awareness about TB and treatment outcome in these patients. Selected patients were visited twice during the study. First at the time of enrolling for the study and second time to assess the outcome.

Ethical clearance was granted by Ethical Clearance Committee of our Institution and other necessary formalities were completed with Directorate of Health Services to access the RNTCP records.

\section{Statistical Analysis}

Data was analysed using SPSS version 17.0.

\section{RESULTS}

\section{General Characteristics}

Out of two hundred and thirty one (231) TB patients studied, $201(86.9 \%)$ were sputum positives, $182(78.7 \%)$ new and 19 $(8.2 \%)$ retreatment cases. Out of these 201 cases $171(85.0 \%)$ were declared cured, 12 (6\%) completed their treatment and out of 29 (12.6\%) Extra Pulmonary Tuberculosis (EPTB) 26 (89.7\%) completed their treatment. Out of 231 cases registered $2.1 \%$ died, $1.8 \%$ defaulted and $0.5 \%$ were failures and 10 were lost to followup. Only one sputum negative case $(0.43 \%)$ could be registered for the study.

\section{Socio-Demographic Characteristics}

Table 2 reveals almost an equal representation of females and males in the studied group ( $51.5 \%$ and 48.5 , respectively). Age of the patients ranged from 5 - 80 years with a mean age of 38 years; $63.2 \%$ of patients belonged to the productive age group of 15 - 45 years of age; $33.4 \%$ patients were above 45 years of age. Only $3.5 \%$ patients belonged to age group less than 15 years.

Majority (70.1\%) of the patients studied belonged to rural areas; $46.3 \%$ of the studied patients were illiterate, $29.4 \%$ had a higher secondary degree and $4.3 \%$ were graduates; $54.5 \%$ of the patients were farmers/agricultural labourers followed by the unemployed group 67 (29.0\%) with only $16.5 \%$ belonging to employed class (Government or Private); $64.0 \%$ patients were married, $66.3 \%$ lived in joint families with $51.9 \%$ living in semi-pucca houses. 
Health and Treatment Seeking Behaviour of Patients Table 3 depicts that almost all 227 (98.3\%) of the patients were concerned about their health and 222 (96.1\%) sought advice in case of a health problem; 217 (93.9\%) reported that they discuss health related issues with others; 145 (62.8\%) reported that they visit health facility alone, rest needed someone to accompany them to visit a health facility; 145 (62.8\%) of the patients preferred Government facility for treatment; $35.5 \%$ had visited the facility on their own as only $29.4 \%$ were sent by health personnel $(10.8 \%$ by local practitioners and $18.6 \%$ by health workers); $21.6 \%$ of patients had sought treatment at TB treatment facility within 1 st week of appearance of symptoms, while $47.6 \%$ had delayed treatment seeking at these facilities for 4 weeks; $85.7 \%$ of TB patients were put on treatment within 3 - 4 days of diagnosis, $13 \%$ within a week and $1.3 \%$ reported a delay of more than 1 week. The differences between health and treatment seeking behaviours were statistically significant $P<0.001$.

Figure 1: Shows rural people were less dependent on others and could visit health facility alone (70\%) compared to urbanites (29\%). Gender wise, there was not much of the difference in attending a health facility.

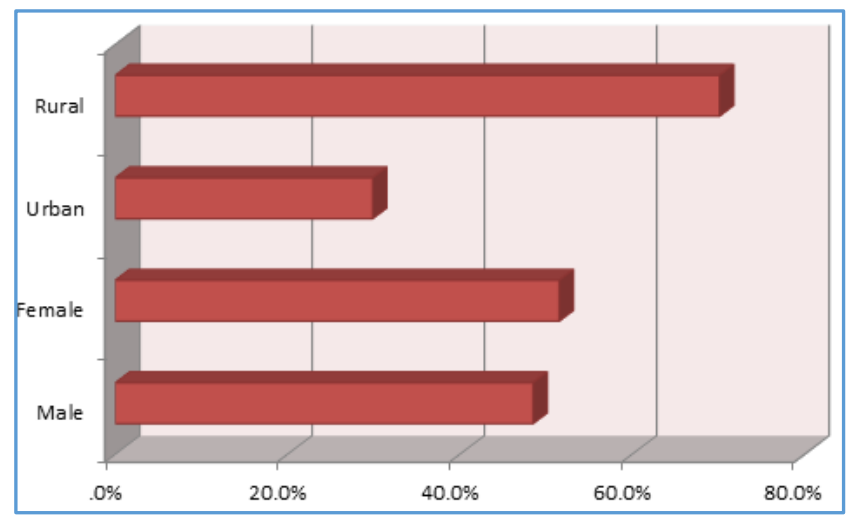

Figure 1. Gender and Residence Wise \% Age of Patients Who Visit Health Facility Alone

Table 4 shows that out of total 231 TB patients, 145 (62.8\%) had delayed their TB treatment seeking; 117 (81\%) delayed their treatment because of their own reasons (patient related reasons), whereas 28 (19\%) had delayed treatment due to reasons attributed to the health system. Among patient related reasons, main cause of delay was having reported to a private health facility $(44.4 \%)$ in the initial stages after appearance of symptoms followed by having neglected their symptoms $35.6 \%$. While as $20.0 \%$ attributed it to financial problems (Lack of money to visit a health facility). Main health system related reason cited by patients was non-availability of nearer health facility (89.3\%) followed by not so good attitude of health workers $(10.7 \%)$. The differences in delaying treatment and the reasons thereof were highly significant. $\mathrm{P}$ value $<0.001$.

Table 5 depicts females had more delay in TB treatment seeking than males $(55.2 \% \mathrm{v} / \mathrm{s} 44.8 \%)$. In half the females, reason of delay was going to private practitioners for treatment of their symptoms and in males it was due to neglecting their symptoms in initial stages for treatment seeking. Delay was more in 15 - 44 years' age group (59.3\%). Rural, illiterate and employed people depicted more delay than urban, literate and unemployed (75.2\% v/s 24.8\%, 57.2\% $\mathrm{v} / \mathrm{s} 42.8 \%$ and $66.9 \% \mathrm{v} / \mathrm{s} 33.1 \%$, respectively). In children less than 15 years, urban dwellers and unemployed visiting a private facility for initial care was the main reason of delay; $23.5 \%$ of rural people reported financial reason for delay as also $46.6 \%$ of unemployed had the same reason. Although, small percentage of people, i.e. $12.1 \%$ reported health system related delay, of these the main reason being non-availability of health facility in the vicinity of their houses $(89.3 \%)$ followed by poor attitude of health workers. The differences by reasons in seeking health care by various sociodemographic variables are statistically significant. *P value < $0.001,{ }^{* *} \mathrm{P}<.027,{ }^{* * *} \mathrm{P}<.013$

\section{Knowledge and Awareness about Various Aspects of TB in Patients}

Table 6 shows that 99 (42.9\%) had correct knowledge of symptoms, 77 (33.3\%) had correct knowledge of transmission and $64(27.7 \%)$ and $130(56.3 \%)$ knew about complications and control of TB respectively. Very small number 30 (13\%) had heard of DOTS and DMC before diagnosis.

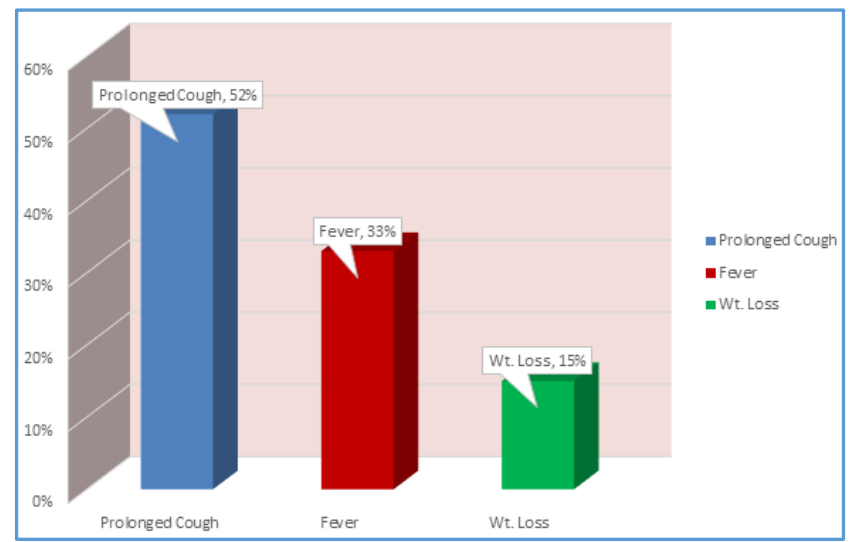

Figure 2. Knowledge about Symptoms of TB in Studied Group

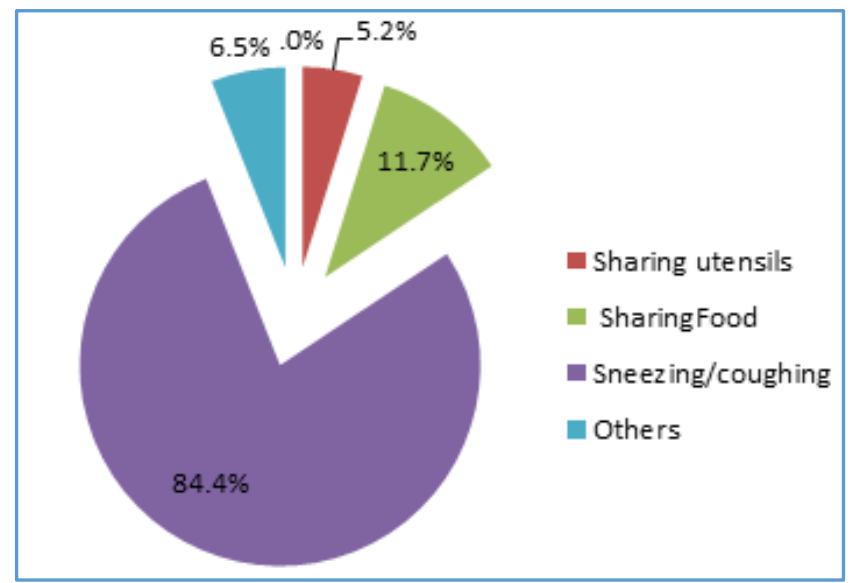

Figure 3. Knowledge about Modes of Transmission of TB in Studied Group

Figure 2 shows of those who had correct knowledge, prolonged cough (52.0\%), fever (33\%) and weight loss (15\%) were thought to be the commonest symptoms of TB. Patients knew about more than one symptom of TB. 
Figure 3 depicts distribution of patients by concept of transmission of TB. Most of the patients answered TB was transmitted by sneezing/coughing (84\%), sharing food with TB patient $(11.7 \%)$, sharing utensils with TB patient $(5.2 \%)$ and others (6.5\%). (Multiple responses were given).

Figure 4 depicts that majority, i.e. $75 \%$ believed that TB lead to early death, $29 \%$ believed patients cough out blood and $17 \%$ thought there occurs failure of respiration (Multiple responses received).

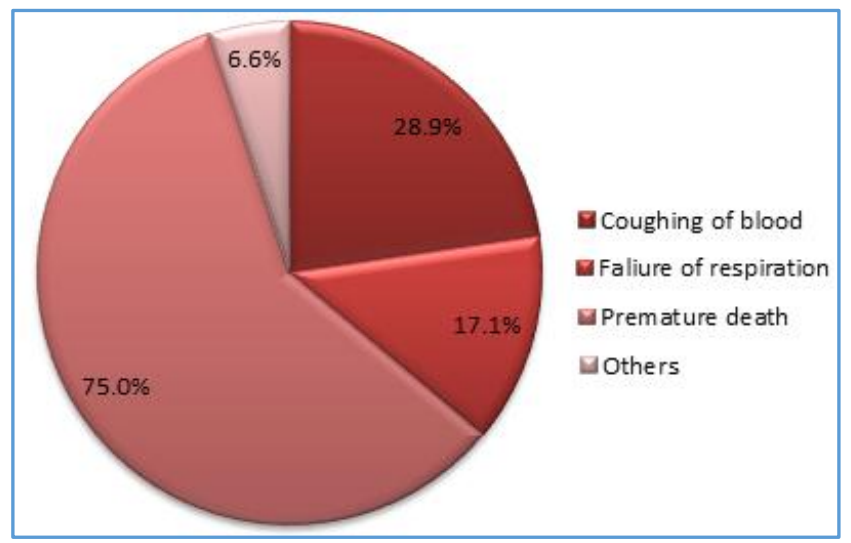

Figure 4. Knowledge about Complications of TB in Studied Group

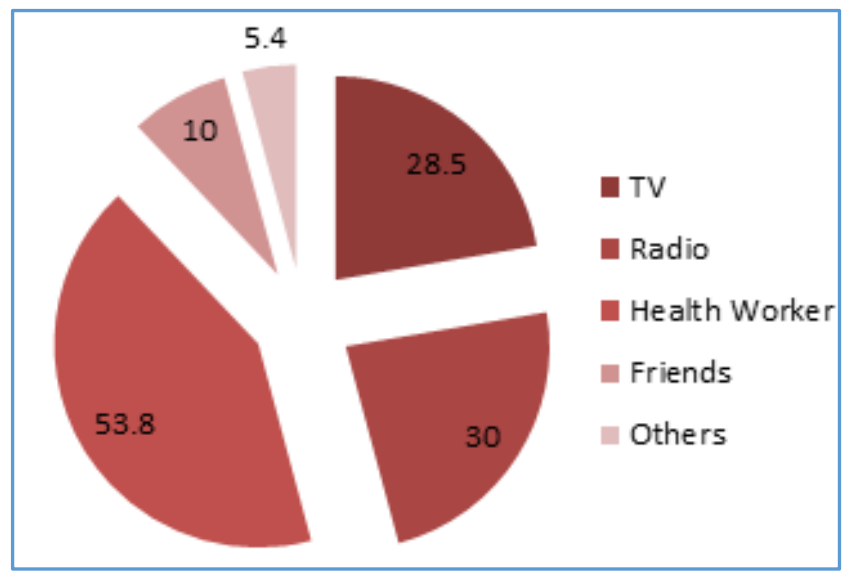

Figure 5. Sources of TB Information in Studied Group

Figure 5 shows that source of TB information was mainly from health workers (53\%) followed by radio (30\%), TV (29\%), others (5\%). (More than one response received).

Table 7 shows that only $61.5 \%$ of TB patients knew they had TB and were on treatment; $50.6 \%$ knew about correct number of drugs and $67.1 \%$ knew correct number of doses they are taking; 59.3\% knew how many sputum examinations they have to undergo while on treatment and $71.4 \%$ knew about the phase of treatment they were on.

\begin{tabular}{|c|c|c|c|c|c|c|c|c|c|c|c|c|c|c|c|}
\hline \multirow[t]{2}{*}{ District } & \multirow{2}{*}{\begin{tabular}{|c|c}
$\begin{array}{c}\text { Total } \\
\text { SPTB } \\
\text { (New + } \\
\text { Retreatment) }\end{array}$ \\
No.
\end{tabular}} & \multicolumn{2}{|c|}{$\begin{array}{c}\text { Cured SPTB } \\
\text { (New + } \\
\text { Retreatment) }\end{array}$} & \multicolumn{2}{|c|}{$\begin{array}{c}\text { Treatment } \\
\text { Completed } \\
\text { in SPTB }\end{array}$} & \multicolumn{2}{|c|}{$\begin{array}{c}\text { Treatment } \\
\text { Completed } \\
\text { in EPTB }\end{array}$} & \multicolumn{2}{|c|}{$\begin{array}{c}\text { Died out } \\
\text { of Total } \\
\text { pts. }\end{array}$} & \multicolumn{2}{|c|}{ Defaulted } & \multicolumn{2}{|c|}{ Failure } & \multicolumn{2}{|c|}{ Total } \\
\hline & & No. & $\%$ & No. & $\%$ & No. & $\%$ & No. & $\%$ & No. & $\%$ & No. & $\%$ & No. & $\%$ \\
\hline Srinagar & 33 & 30 & 90.9 & 2 & 6.1 & 11 & 91.7 & nil & & 1 & 2.2 & nil & & 45 & 19.5 \\
\hline Budgam & 23 & 22 & \begin{tabular}{|l|}
95.7 \\
\end{tabular} & nil & & nil & & nil & & 1 & 4.1 & nil & & 24 & 10.4 \\
\hline Baramulla & 39 & 31 & 79.5 & 5 & 12.8 & 6 & 85.7 & 1 & 2.1 & 1 & 2.1 & nil & & 46 & 19.9 \\
\hline Kupwara & 30 & 23 & 76.7 & 3 & 10.0 & 4 & 100.0 & 2 & 5.8 & nil & & nil & & 34 & 14.7 \\
\hline Anantnag & 33 & 23 & 69.7 & 2 & 6.1 & 2 & 100.0 & 2 & 5.7 & 1 & 2.8 & nil & & 35 & 15.2 \\
\hline Pulwama & 43 & 42 & 97.7 & nil & & 3 & 75.0 & nil & & nil & & 1 & 2.1 & 47 & 20.3 \\
\hline Total & 201 & 171 & 85.1 & 12 & 6.0 & 26 & 89.7 & 5 & 2.1 & 4 & 1.8 & 1 & 0.5 & 231 & 100.0 \\
\hline
\end{tabular}

\begin{tabular}{|c|c|c|c|}
\hline \multirow{2}{*}{\multicolumn{2}{|c|}{ Characteristics }} & \multicolumn{2}{|c|}{ Diagnosed TB Patients } \\
\hline & & \multirow{2}{*}{$\begin{array}{l}\text { No. } \\
112\end{array}$} & \multirow{2}{*}{$\begin{array}{c}\text { Percentage (\%) } \\
48.5\end{array}$} \\
\hline Syy & Male & & \\
\hline sex & Female & 119 & 51.5 \\
\hline \multirow{5}{*}{ Age in Years } & $<15$ & 8 & 3.5 \\
\hline & $15-29$ & 86 & 37.2 \\
\hline & $30-44$ & 60 & 26.0 \\
\hline & $45-59$ & 26 & 11.3 \\
\hline & $60+$ & 51 & 22.1 \\
\hline \multirow{2}{*}{ Place of Residence } & Urban & 69 & 29.9 \\
\hline & Rural & 162 & 70.1 \\
\hline \multirow{4}{*}{ Education } & Graduate & 10 & 4.3 \\
\hline & Higher Secondary & 68 & 29.4 \\
\hline & High and Middle & 46 & 19.9 \\
\hline & Illiterate & 107 & 46.3 \\
\hline Occupation & Govt./Private Service & 38 & 16.5 \\
\hline
\end{tabular}




\begin{tabular}{|c|c|c|c|}
\hline \multirow{2}{*}{ Marital Status } & Agriculture/Labourer & 126 & 54.5 \\
& Unemployed & 67 & 29.0 \\
& Married & 148 & 64.0 \\
& Unmarried & 64 & 27.8 \\
\cline { 2 - 4 } & Widowed & 19 & 8.2 \\
\cline { 2 - 4 } & Nuclear & 78 & 33.7 \\
\hline \multirow{2}{*}{ Family Type } & Joint & 20 & 66.3 \\
\cline { 2 - 4 } & Katcha & 120 & \multicolumn{2}{|c|}{51.9} \\
\hline Housing & Semi-Pucca & \multicolumn{2}{|c|}{39.4} \\
\hline & Pucca & $\mathbf{1 0 0 . 0}$ \\
\hline
\end{tabular}

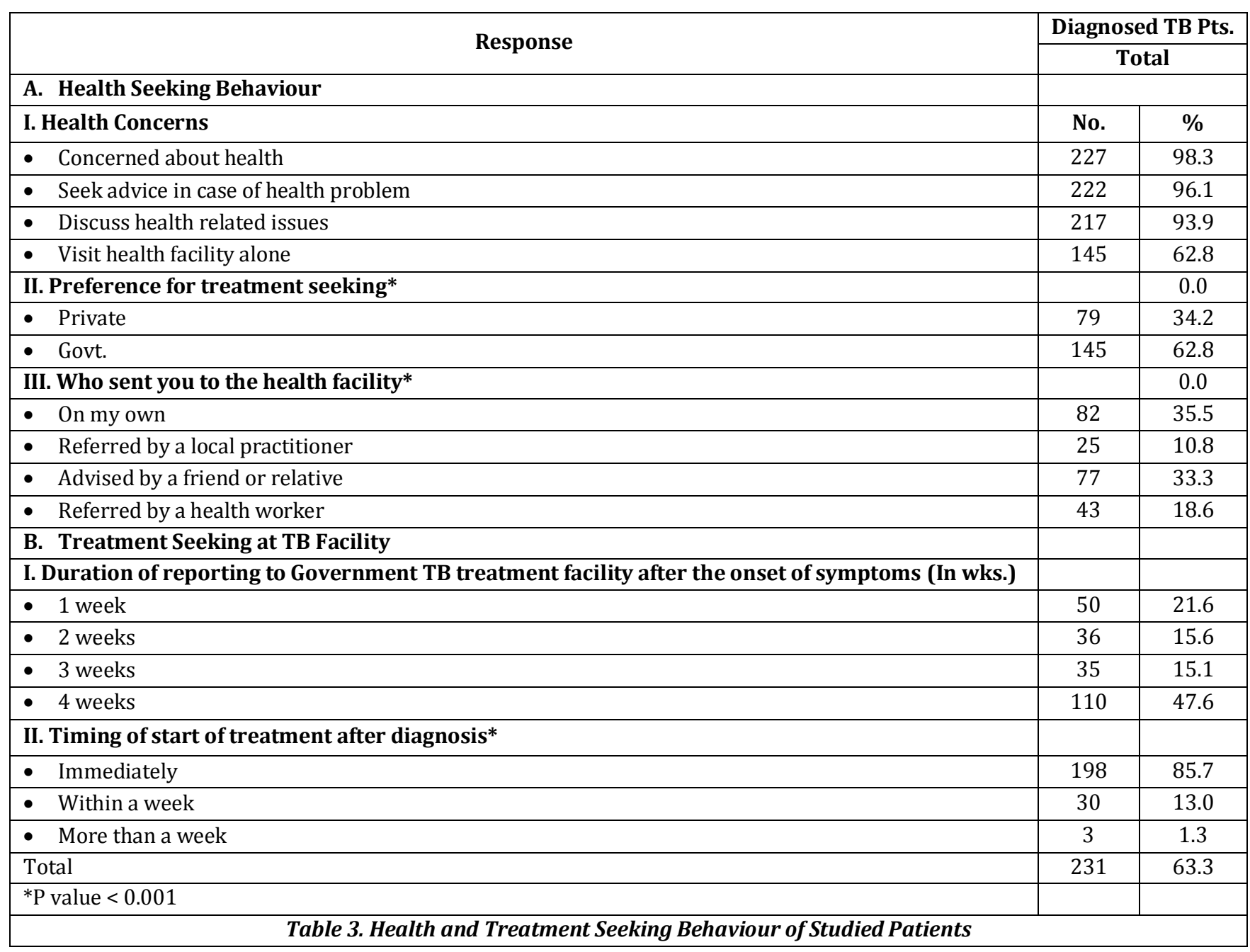

\begin{tabular}{|l|c|c|c|}
\hline \multicolumn{1}{|c|}{ Delay in Treatment Due To } & No. & \% & \\
\hline A. Patient Related Reasons: & $117^{*}$ & 80.7 & $\mathrm{P}<0.001$ \\
\hline$\bullet \quad$ Neglected symptoms & $42^{*}$ & 35.6 & \\
\hline$\bullet \quad$ Reported to Private Facility & 52 & 44.4 & \\
\hline$\bullet \quad$ Financial problem & 23 & 20.0 & $\mathrm{P}<0.001$ \\
\hline B. Health System Related Reasons: & $28^{*}$ & 19.3 & $\mathrm{P}<0.001$ \\
\hline$\bullet \quad$ No Health Facility in area & $25^{*}$ & 89.3 & \\
\hline$\bullet \quad$ Behaviour of Health Workers not good & 3 & 10.7 & $\mathrm{P}<0.001$ \\
\hline Total with delay & $145^{*}$ & 62.8 & $\mathrm{P}<0.001$ \\
\hline \multicolumn{2}{|}{ Table 4. Reasons for Delayed Treatment Seeking at Designated Government TB Treatment Facility by Patients } \\
\hline
\end{tabular}

Differences are statistically significant $\mathrm{P}<0.001$ 


\begin{tabular}{|c|c|c|c|c|c|c|c|c|c|c|c|c|c|c|c|c|c|}
\hline \multirow{2}{*}{\multicolumn{2}{|c|}{ Characteristics }} & \multicolumn{10}{|c|}{ Patient Related Reasons } & \multicolumn{6}{|c|}{ Health System Related Reasons } \\
\hline & & \multicolumn{2}{|c|}{$\begin{array}{l}\text { Overall } \\
\text { with } \\
\text { Delay }\end{array}$} & \multicolumn{2}{|c|}{$\begin{array}{l}\text { Total with } \\
\text { Patient } \\
\text { Related } \\
\text { Reasons of } \\
\text { Delay }\end{array}$} & \multicolumn{2}{|c|}{$\begin{array}{l}\text { Neglected } \\
\text { Symptoms }\end{array}$} & \multicolumn{2}{|c|}{$\begin{array}{l}\text { Reported to } \\
\text { Private } \\
\text { Facility }\end{array}$} & \multicolumn{2}{|c|}{$\begin{array}{l}\text { Financial } \\
\text { Problem }\end{array}$} & \multicolumn{2}{|c|}{$\begin{array}{l}\text { Total with } \\
\text { Health } \\
\text { System } \\
\text { Related } \\
\text { Reasons } \\
\text { of Delay }\end{array}$} & \multicolumn{2}{|c|}{$\begin{array}{c}\text { No Health } \\
\text { Facility in } \\
\text { Area }\end{array}$} & \multicolumn{2}{|c|}{$\begin{array}{c}\text { Attitude } \\
\text { of Health } \\
\text { Workers } \\
\text { Not Good }\end{array}$} \\
\hline & & No. & $\%$ & No. & $\%$ & No. & $\%$ & No. & $\%$ & No. & $\%$ & No. & $\%$ & No. & $\%$ & No. & $\%$ \\
\hline \multirow{2}{*}{ Sex } & Male & $65^{*}$ & 44.8 & 48 & 73.8 & $25^{* *}$ & 52.0 & $17^{* * *}$ & 35.4 & $6^{* *}$ & 12.5 & 17 & 26.2 & $15^{*}$ & 88.2 & 2 & $\begin{array}{c}11 . \\
8\end{array}$ \\
\hline & Female & 80 & 55.2 & 69 & 86.3 & 17 & 24.6 & 35 & 50.7 & 17 & 24.6 & 11 & 13.8 & 10 & 90.9 & 1 & 9.1 \\
\hline \multirow{5}{*}{ Age in Years } & $<15$ & $4^{*}$ & 2.8 & 4 & 100.0 & 0 & & 4 & 100 & 0 & 0 & 0 & 0.0 & 0 & 0 & 0 & 0 \\
\hline & $15-29$ & 42 & 29.0 & 33 & 78.6 & 13 & 39.3 & 10 & 30.3 & 10 & 30.3 & 9 & 21.4 & $8^{*}$ & 88.8 & 1 & $\begin{array}{c}11 . \\
1\end{array}$ \\
\hline & $30-44$ & 44 & 30.3 & 35 & 79.5 & 11 & 31.4 & 18 & 51.4 & 6 & 17.1 & 9 & 20.5 & 9 & 100 & 0 & 0 \\
\hline & $45-59$ & 25 & 17.2 & 18 & 72.0 & 9 & 50 & 8 & 44.4 & 1 & 5.5 & 7 & 28.0 & 6 & 85.7 & 1 & $\begin{array}{c}14 . \\
2\end{array}$ \\
\hline & $60+$ & 30 & 20.7 & 27 & 90.0 & 9 & 33.3 & 12 & 44.4 & 6 & 22.2 & 3 & 10.0 & 2 & 66.6 & 1 & $\begin{array}{c}43 . \\
3\end{array}$ \\
\hline \multirow{2}{*}{$\begin{array}{l}\text { Place of } \\
\text { Residence }\end{array}$} & Urban & $36^{*}$ & 24.8 & 32 & 88.9 & 11 & 34.3 & $18^{* *}$ & 56.2 & $3^{*}$ & 9.3 & $4^{*}$ & 11.1 & 4 & 100.0 & 0 & .0 \\
\hline & Rural & 109 & 75.2 & 85 & 78.0 & 31 & 36.4 & 34 & 40.0 & 20 & 23.5 & 24 & 22.0 & 21 & 87.5 & 3 & $\begin{array}{c}12 . \\
5\end{array}$ \\
\hline \multirow{2}{*}{ Education } & Literate & $62^{*}$ & 42.8 & 54 & 87.1 & 21 & 38.8 & 27 & 50 & 6 & 11.1 & 8 & 12.9 & $6^{*}$ & 75 & 2 & 25 \\
\hline & Illiterate & 83 & 57.2 & 63 & 75.9 & 21 & 33.3 & 25 & 39.6 & 17 & 26.9 & 20 & 24.1 & 19 & 95 & 1 & 5 \\
\hline \multirow{3}{*}{ Occupation } & Employed & $97^{*}$ & 66.9 & 87 & 89.7 & $40^{*}$ & 45.9 & 38 & 43.6 & $9^{*}$ & 10.3 & 10 & 10.3 & 10 & 100 & 0 & 0 \\
\hline & Unemployed & 48 & 33.1 & 30 & 62.5 & 2 & 6.6 & 14 & 46.6 & 14 & 46.6 & 18 & 37.5 & 15 & 83.3 & 3 & $\begin{array}{c}16 . \\
6\end{array}$ \\
\hline & Total & $\begin{array}{c}145 \\
*\end{array}$ & 62.8 & $117^{*}$ & 80.7 & $42^{*}$ & 35.6 & $52^{*}$ & 44.4 & $23^{*}$ & 20.0 & $28^{*}$ & 19.3 & $25^{*}$ & 89.3 & $3^{*}$ & $\begin{array}{c}10 . \\
7\end{array}$ \\
\hline
\end{tabular}

${ }^{*} \mathrm{P}$ value $<0.001,{ }^{* *} \mathrm{P}<.027,{ }^{* * *} \mathrm{P}<.013$

\begin{tabular}{|c|c|c|}
\hline \multirow{2}{*}{ Knowledge About TB } & \multicolumn{2}{|c|}{ Correct Knowledge } \\
\hline & No. & $\%$ \\
\hline Symptoms & 99 & 42.9 \\
\hline Transmission & 77 & 33.3 \\
\hline Complications & 64 & 27.7 \\
\hline Control & 130 & 56.3 \\
\hline DOTS & 30 & 13.0 \\
\hline DMC & 30 & 13.0 \\
\hline Total & 231 & 63.3 \\
\hline \multicolumn{3}{|c|}{$\begin{array}{c}\text { Table 6. Knowledge Among Studied } \\
\text { Patients regarding TB }\end{array}$} \\
\hline
\end{tabular}

\begin{tabular}{|c|c|c|}
\hline Have Knowledge About & No. & $\%$ \\
\hline TB treatment & 142 & 61.5 \\
\hline Number of drugs to be taken & 117 & 50.6 \\
\hline Number of doses required & 155 & 67.1 \\
\hline Phase of treatment & 165 & 71.4 \\
\hline Sputum exam while on DOTS & 137 & 59.3 \\
\hline Total & 231 & 63.3 \\
\hline \multicolumn{3}{|c|}{$\begin{array}{l}\text { Table 7. Knowledge of TB Patients about Treatment } \\
\text { They Are On }\end{array}$} \\
\hline
\end{tabular}

\section{DISCUSSION}

Study reveals almost an equal representation of females and males in the registered group contrary to most of the studies, which show male preponderance. In other words, TB prevalence is on higher side in females in this part of the country. Majority of the patients studied belonged to the productive age group of 15 - 45 (63.2\%) (mean 38 and median $35), 2 / 3$ rd (65.5\%) of patients belonged to rural area. Literacy status did not differ much among patients, but lesser number of patients with higher education (graduates and above) were registered. More of agricultural labourers/farmers (51.8\%) and unemployed $(32.9 \%)$ were registered showing increased prevalence of disease in them than those working in Government or Private sector. Study conducted by Dana Schneider et al(8) in 2010 showed $80 \%$ were males, $54 \%$ were married, $82 \%$ were unemployed, $10 \%$ had less than a junior high education. Ages of participants ranged from $8-77$ (mean: 38.1; median: 38). Esther S Ngadaya et al(9) 2009 report that the majority $(66.5 \%)$ of the patients were males. Their mean (SD) and median age was 37.3 (14.5) and 35 years respectively. Mean (SD) and median age for females was 33.7 (12.8) and 31 years. Likewise in a study by P. Sukumaran et al,(10) males outnumbered females by more than three to one. Approximately, $64 \%$ patients were in the economically productive age group (20 - 50 years). All the patients were from the lower socio-economic stratum; $45 \%$ were manual labourers and $8 \%$ were nursing students (33\% of all females). Although almost all were concerned about health and equal number admitted that they seek advice in case of health problems, $62.8 \%$ patients had delayed TB treatment seeking for more than 4 weeks and half of them (50.6\%) had done so because of the personal reasons like initial neglect of symptoms in $(35.6 \%)$ or financial reasons in $(20.0 \%)$. A large segment of patients (44.4\%) got delayed diagnosis or treatment as they had initially reported to private practitioners without getting correctly diagnosed for TB. Health system related delay, though less (12.1\%), still contributes its part in getting delayed TB treatment and mostly attributed it to non-availability of Health Facility 
nearer to their homes. Rural (75.2\%), illiterate (57.2\%) and employed (66.9\%) depicted more delay in health seeking. A systematic review by Chandrashekhar T S(4) from India shows that patient and health system delays are considerable, and may partially explain the current epidemiology of TB and report that a sizeable fraction of persons with PTB or presumed PTB first visit informal and private sector providers, particularly in urban areas and multiple visits to HCPs appears to be an important risk factor for total delay.

Hussen $A^{(11)}$ in their study report patient's delay was positively associated with first visit to traditional healer/private clinic/drug shop, rural residence, being illiterate, living in more than 10 kilometres from Health Facility; severity of illness at first presentation to Health Facility. Provider delay was positively associated with rural residence, being illiterate, patient with good functional status, patients in contact with more than two health providers and place of first visit being traditional healer/private clinic/drug shop. Same has been reported by Yimer SA.(12)

Dana Schneider et $\mathrm{al}^{(8)}$ report that $86 \%$ first sought medical care in the public sector. The remaining $14 \%$ participants first sought care from the private sector. A systematic review by Dag G S et al(13) shows that several papers report multiple visits at the same level without a correct diagnosis, while others focus on multiple visits to the same physician. Three groups of healthcare providers were particularly identified as sources of this vicious circle: Primary Level Government Health Posts, who have limited diagnostic facilities and poorly trained personnel, private practitioners with low awareness of TB and unqualified vendors, quacks and traditional practitioners. Most of the studies whether investigating low or high endemic countries, reported a total diagnostic delay within the range of 60 - 90 days (mean \pm standard deviation: 72 days \pm 28 days). The longest total delays ( $>120$ days) were reported for some high endemic countries. Twelve studies reported a nearly equal contribution of patients and healthcare system to the diagnostic delay. A median 126-day delay was reported by Lewis et al(14) for East London. In a study in Malaysia,(15) only $11 \%$ of patients received their diagnosis after the first consultation and $45 \%$ received their first diagnosis after the third consultation. Another study from Malaysia similarly indicates low awareness of the private practitioner as a key problem.(16) In a study from Malawi, the median patient delay was 14 days for both new and retreatment TB cases. The median health system delay was 59 days for new and 40.5 days for retreatment cases.(17)

While assessing the knowledge of registered cases regarding $\mathrm{TB}$, it was found that the knowledge regarding symptoms transmission, prevention, duration of standard treatment and DOTS was low as only half (51.5\%) of the patients had heard of TB and lesser than half (42.7\%) had correct knowledge of symptoms. Knowledge further decreased to $34.5 \%$ and $28.8 \%$ regarding transmission and complications respectively. Situation was even worse regarding their knowledge about DMC and DOTS $34.2 \%$ and $16.4 \%$, respectively). Regarding knowledge of TB patients about treatment they are on, only $2 / 3$ rd (61.5\%) knew that they were on anti-tuberculosis treatment, rest thought it was a weakness in the chest or some thought they were taking health tonics. Only half (50.6\%) of them could answer the exact number of drugs they are on, 2/3rd knew the number of doses they take in a week, 3/4th knew about phase of treatment and $59.3 \%$ knew about correct number of sputum examinations to be done while on DOTS. D S Hashim(18) in a study in Iraq reported $64.4 \%$ of patients had good knowledge, $61.0 \%$ said cough is transmitted by cough while $55.4 \%$ mentioned breathing and the rest mentioned spitting, kissing, touching or food $(26.8 \%, 20.8 \%, 20.6 \%, 15.2 \%$ respectively). The source of information about TB was the physician for $27.5 \%$ of patients, the mass media (mainly television) for $23.2 \%$ and 'life experience' for $16.0 \%$. Concerning the consequences of interrupted treatment, $59.0 \%$ of patients believed that TB would never be cured and $27.0 \%$ believed that it would result in death.

Pieter $\mathrm{J} \mathrm{H}$ et al(19) report that the Maasai population is aware of the danger TB poses; $67 \%$ of the population knows about TB, $80 \%$ knows the symptoms and $67 \%$ knows it is treatable; however, less than half had knowledge in areas concerning prevention, causality, treatment and adherence. Muhammad U et al(20) in their study revealed poor knowledge regarding TB. The deficit was greater in the rural areas in all aspects. The knowledge regarding symptoms transmission, prevention, duration of standard treatment and DOTS was significantly higher in the urban areas (all $\mathrm{P}<0.001$ ). Although, most the subjects (urban 83.8\%, rural 81.2\%) were aware of the correct treatment for TB, less than half (urban $48.1 \%$, rural $49.2 \%$ ) were aware of the availability of the diagnostic facility and treatment free of cost. The practice of seeking treatment at a health facility as soon as they realised that they had TB symptoms $(\mathrm{P}<0.001$; was significantly higher in the urban areas. People in the urban areas were more likely to feel ashamed and embarrassed being a TB patient $(\mathrm{P}<$ 0.001); however, they seem to be supportive in case their family member suffered from TB $(\mathrm{P}=0.005)$. Nearly half of the respondents, irrespective of the area of residence believed that the community rejects the TB patient (urban $49.8 \%$, rural 46.4\%). Television (urban $80.1 \%$, rural $68.1 \%$ ) and health workers (urban $30.6 \%$, rural $41.4 \%$ ) were the main sources for people to acquire the TB related information. Sekandi J N et al(21) have observed that there are four degrees of separation between the onset of symptoms in a TB patient and a final diagnosis. Both social and provider networks of patients influenced the diagnostic pathways. Most delays occurred in the first step, which represents decisions to seek help and through interactions with non-TB health providers.

\section{CONCLUSION}

The study revealed a significant delay in TB detection in studied patients. The reasons given by a good proportion of patients for the delay included seeking treatment from private practitioners initially for their symptoms besides an actual delay in seeking care by the patients by neglecting symptoms due to poor knowledge about the disease. It also reveals that health workers need to be geared up for TB detection.

\section{Recommendations}

Enhancing early case detection by active case finding among high-risk groups and by contact tracing. There is also a need to intensify TB case finding through community mobile services. Fear of stigma and poor knowledge about disease needs to be overcome by influencing people's health seeking behaviour through health communication and social mobilisation programmes. Raising awareness about TB, its symptoms and 
TB care services in the community that will help ensure that people do not neglect TB symptoms and take appropriate action early and approach the right facility for care. Ensuring client satisfaction remains key to successful communication to the community about the utility of the available TB services. Cured TB patients can be actively involved to increase awareness in the community and also be formally engaged to identify and refer people with TB symptoms. Community participation as well as the rights of the patient for the diagnosis and treatment needs to be enforced and emphasised. All the private practitioners should be brought under the purview of RNTCP. Delay in employed class can be reduced through benefits of sick leaves for them.

\section{Strengths}

Study includes a heterogeneous population of TB patients coming from different levels of the health care system from different regions and with a rural and urban mix, and therefore is representative of the overall TB programme in the Valley.

\section{Limitations}

Limitations of the study include a possibility of recall bias of past events among respondents relating to when they first encountered TB symptoms. In order to minimise patient recall bias, we encouraged them to show medical records related to this event. Due to the nature of the cross-sectional study design under reporting or over reporting of patient delay is unavoidable. There is also a possibility that our patient sample excluded vital information on those patients who may have been suspected of TB or diagnosed of TB in the private sector, but did not go to Public Health Facilities despite being referred.

\section{Acknowledgement}

We are thankful to Central TB Division Health and Family Welfare, Government of India, for funding this Research. Our sincere thanks to all the patients and participants of this Research.

\section{REFERENCES}

1. TB INDIA 2016. Revised national TB control programme. Annual status report.

2. Ahmad T. Tuberculosis in India-multidimensional analysis. INSIGHTS 2014. http://www.insightsonindia.com/2014/01/02/tuberculo sis-in-india-multidimensional-analysis.

3. Dye C, Williams BG. The population dynamics and control of tuberculosis. Science 2010;328(5980):856-61.

4. Sreeramareddy CT, Qin ZZ, Satyanarayana S, et al. Delays in diagnosis and treatment of pulmonary tuberculosis in India: a systematic review. Int J Tuberc Lung Dis 2014;18(3):255-66.

5. Behra D. Expanding dots--new strategies for TB control? Indian J Tuberc 2010;57(2):63-6.

6. Machado AC, Steffen RE, Oxlade O, et al. Factors associated with delayed diagnosis of pulmonary tuberculosis in the state of Rio de Janeiro, Brazil. J Bras Pneumol 2011;37(4): 512-20.

7. Official documents of State Tuberculosis officer. Kashmir Division. 2011.

8. Schneider D, McNabb SJN, Safaryan M, et al. Reasons for delay in seeking care for tuberculosis, republic of Armenia, 2006-2007. Interdisciplinary Perspectives on Infectious Diseases 2010;2010:1-8.

9. Ngadaya ES, Mfinanga GS, Wandwalo ER, et al. Delay in tuberculosis case detection in Pwani region, Tanzania. A cross sectional study. BMC Health Serv Res 2009;9:196.

10. Sukumaran P, Venugopal KP, Manjooran RS. A social study of compliance with dots. Ind J Tub 2002;49:205-8.

11. Hussen A, Biadgilign S, Tessema F, et al. Treatment delay among pulmonary tuberculosis patients in pastoralist communities in Bale Zone, Southeast Ethiopia. BMC Res Notes 2012;5:320.

12. Yimer SA, Bjune GA, Holm-Hansen C. Time to first consultation, diagnosis and treatment of TB among patients attending a referral hospital in Northwest, Ethiopia. BMC Infect Dis 2014;14:19.

13. Storla DG, Yimer S, Bjune GA. A systematic review of delay in the diagnosis and treatment of tuberculosis. BMC Public Health 2008;8:15.

14. Lewis KE, Stephens C, Shahidi MM, et al. Delay in starting treatment for tuberculosis in east London. Commun Dis Public Health 2003;6(2):133-8.

15. Hooi LN. Case-finding for pulmonary tuberculosis in Penang. Med J Malaysia 1994;49(3):223-30.

16. Liam CK, Tang BG. Delay in the diagnosis and treatment of pulmonary tuberculosis in patients attending a university teaching hospital. Int J Tuberc Lung Dis 1997;1(4):326-32.

17. Makwakwa L, Sheu ML, Chiang CY, et al. Patient and heath system delays in the diagnosis and treatment of new and retreatment pulmonary tuberculosis cases in Malawi. BMC Infect Dis 2014;14:132.

18. Hashim DS, Al Kubaisy W, Al Dulayme A. Knowledge, attitudes and practices survey among health care workers and tuberculosis patients in Iraq. East Mediterr Health J 2003;9(4):718-31.

19. Haasnoot PJ, Boeting TE, Kuney MO, et al. Knowledge, attitudes, and practice of tuberculosis among maasai in Simanjiro District, Tanzania. Am J Trop Med Hyg 2010;83(4):902-5.

20. Mushtaq MU, Shahid U, Abdullah HM, et al. Urban-rural inequities in knowledge, attitudes and practices regarding tuberculosis in two districts of Pakistan's Punjab province. Int J Equity Health 2011;10:8.

21. Sekandi JN, Zalwango S, Martinez L, et al. Four degrees of separation: social contacts and health providers influence the steps to final diagnosis of active tuberculosis patients in urban Uganda. BMC Infect Dis 2015; 15:361. 